\title{
PREDICTORS OF WEIGHT LOSS IN PATIENTS WITH CHRONIC HEART FAILURE AND REDUSED LEFT VENTRICULAR EJECTION FRACTION
}

\author{
Kateryna Voitsekhovska ${ }^{1}$ \\ e_voitsekhovskaya@ukr.net \\ Leonid Voronkov ${ }^{l}$ \\ lgvoronkov@gmail.com \\ ${ }^{1}$ Department of heart failure \\ NSC Institute of Cardiology M. D. Strazhesko \\ National Scientific Center "M. D. Strazhesko Institute of Cardiology" \\ 5 Narodnoho Opolchennya str., Kyiv, Ukraine, 02000
}

\begin{abstract}
Chronic heart failure (CHF) is a heterogeneous syndrome with a poor prognosis.

Aim of the work - to define predictors of body weight (BW) loss in patients with CHF and a reduced left ventricular ejection fraction (LVEF).

Materials and methods. 120 patients with stable CHF and LVEF $\leq 35 \%$, II-IV NYHA class were examined. Patients were divided into two groups according to the value of BW loss for 6 months: the first group - loss of BW $<6 \%$, the second $-\geq 6 \%$.

Results. Out of the 120 patients who were studied, a BW loss of $\geq 6 \%$ occurred in 59 (49.2\%) patients. According to the results of binary logistic regression, predictors of BW loss of $\geq 6 \%$ in patients with $\mathrm{CHF}$ and LVEF $\leq 35 \%$ were: age, coronary heart disease, anaemia, and the number of hospitalizations over the last year. People with poorer quality of life, bigger number of points on the Beck depression scale and DEFS, with lower levels of physical activity and worse endothelium-dependent vasodilator response; higher sizes of the right atrium, right ventricle, and pulmonary artery systolic pressure, E/E'. Higher levels of C-reactive protein (CRP), uric acid are associated with a risk of losing $\mathrm{BW} \geq 6 \%$.

Conclusions. Weight loss $\geq 6 \%$ is observed in $49.2 \%$ of patients with CHF and LVEF $\leq 35 \%$. According to multivariate analysis, independent predictors of BW loss of $\geq 6 \%$ in patients with CHF and LVEF $\leq 35 \%$ are age, CRP level, III-IV NYHA class, lower cholesterol levels, as well as lower rates of flow-dependent vasodilator response and hip circumference.
\end{abstract}

Keywords: chronic heart failure, weight loss, cardiac cachexia, predictors.

DOI: $10.21303 / 2504-5679.2019 .00999$

\section{Introduction}

Chronic heart failure (CHF) is a heterogeneous syndrome with a poor prognosis, independent predictors of which are neurohormonal activity disorders [1] and the development of cachexia. Cardiac cachexia is known to be a factor in reducing survival in CHF, regardless of other important variables, such as age, functional class, ejection fraction and physical capabilities [2, 3]. According to statistical estimates, the prevalence of unintentional weight loss, defined as a loss of $6 \%$ or more of body weight over 6 months, ranges from 12 to $16 \%$ in stable outpatients with heart failure (HF) [4], up to $50 \%$ in patients with severe $\mathrm{CH}$ [5]. It was found that the mortality rate of patients with heart failure and progressive weight loss (BW) can reach $50 \%$ within 18 months [6]. The pathophysiological mechanisms underlying the loss of BW in patients with CHF are not entirely understandable; a number of factors have been identified that lead to an imbalance of catabolic and anabolic processes [7]. On the other hand, the clinical characteristics of patients with CHF associated with their loss of BW have been little studied.

Aim of the research - to define the predictors of BW loss in patients with CHF and reduced left ventricular ejection fraction (LVEF).

\section{Materials and methods}

120 hemodynamically stable patients with CHF ( 97 men, 23 women), 18-75 years old (mean age $61 \pm 0.86)$ II-IV NYHA class, with left ventricular ejection fraction (LVEF) $\leq 35 \%$ were exam- 
ined and observed on the basis of the heart failure department of the State Institution "National Scientific Center "Institute of Cardiology named after Acad. N. D. Strazhesko" from 2014 to 2019.

Inclusion criteria. The study included patients aged 18-75 years with clinical signs of CHF, II-IV NYHA class, LVEF $\leq 35 \%$, the etiological factor of CHF of which was coronary heart disease (CHD), including in combination with arterial hypertension $(\mathrm{AH})$ or dilated cardiomyopathy (DCMP).

Exclusion criteria. The study did not include patients over the age of 75 , with acquired and congenital heart defects, gastrointestinal diseases in the acute stage, which limit the ability to eat or are characterized by malabsorption syndrome, hypo- and hyperthyroidism, myocardial infarction, cerebral stroke, or thromboembolism of pulmonary artery branches up to 3 months old, inflammatory and restrictive heart disease, insulin-dependent diabetes mellitus, chronic pulmonary heart disease, chronic renal failure stage $\mathrm{V}$, terminal stage of liver failure, bronchial asthma or chronic obstructive pulmonary disease of the III-IV stages, oncological and infectious diseases.

The members of the Ethics Commission (extract from protocol No. 2 dated January 20, 2014) at the State Institution "National Scientific Center "Institute of Cardiology named after academician N.D. Strazhesko" of the National Academy of Medical Sciences of Ukraine decided that this study would not contradict the main provisions of the GCP, Convention Council of Europe on human rights and biomedicine, the Helsinki Declaration of the World Medical Association on ethical principles for the conduct of scientific medical research with the participation of man and the Law of Ukraine "On Medicines". All patients signed an informed consent to participate in a clinical trial.

The diagnosis of the underlying disease was determined on the basis of a general clinical examination, special instrumental and laboratory methods. CHF was diagnosed according to the recommendations for the diagnosis and treatment of heart failure of the European Society of Cardiology and the relevant recommendations of the Association of Cardiology of Ukraine [8, 9]. Patients were included in the study in the phase of clinical compensation.

The compulsory examination protocol included electrocardiography, standard echocardiography [10], routine laboratory tests (general clinical and biochemical), glomerular filtration rate using the EPI formula [11], an assessment of life quality using the Minnesota Living with Heart Failure Questionnaire (MLHFQ), an assessment of physical activity level using the Duke University questionnaire $[12 ; 13]$, an assessment of psychological status on the Beck Depression scale [14], and an assessment of fatigue after physical exertion on the DEFS (Dutch Exertion Fatigue Scale) scale [15]. All patients underwent a general clinical physical examination, measuring the thickness of the skin-fat fold (SFF) at four points using a caliper, measuring the circumference of the shoulder of an unstrained and tense arm, waist and hip. Evaluation of the vasodilating function of the endothelium (flow-mediated vasodilation - FMV) was carried out using the ultrasonographic method using a sample with reactive hyperaemia [16]. The functional capabilities of the patients were investigated using a standard test with 6-minute walking and a standardized test with extension of the lower extremity, the results of which evaluated the exposure of the quadriceps femoris. The criterion for the patients distribution into groups was the value of weight loss for the last 6 months that preceded the patient inclusion in the study, $\geq 6 \%$ according to the European recommendations for the diagnosis and treatment of CHF [8]. Information on the dynamics of body weight for the specified period was obtained from medical history data and data from medical records of patients.

Statistical processing of information was carried out using Microsoft Exel programs, IBM SPSS Statistics (version 23.0). At the first stage, BW loss factors were tested using binary logistic regression (univariate analysis); uncorrelated odds ratios (ORs) and $95 \%$ confidence intervals (CIs) were calculated. At the next stage of our work, statistically significant factors of BW loss $(p<0.05)$ were consistently included in the multivariate logistic regression model. In a multidimensional model, factors were excluded when pair correlation gave a high linear correlation coefficient $(r>0.7)$. The quality of multivariate logistic regression was determined based on a likelihood comparison test. (Likelihood Ratio Test). 


\section{Results}

Out of the 120 patients who were studied, a BW loss of $\geq 6 \%$ occurred in $59(49.2 \%)$ patients. Their clinical characteristics are presented in Table $\mathbf{1}$.

Table 1

Clinical characteristics and pharmacotherapy structure of patients with CHF and reduced LVEF

\begin{tabular}{ccc}
\hline Parameter & $\mathbf{n}$ & $\mathbf{\%}$ \\
\hline Number of patients & 120 & 100 \\
Men & 97 & 80.8 \\
CHD & 104 & 86.7 \\
DCMP & 15 & 12.5 \\
Hypertension & 102 & 85.0 \\
MI & 49 & 40.8 \\
AF & 69 & 57.5 \\
II NYHA class & 46 & 38.3 \\
III-IV NYHA class & 74 & 61.7 \\
Anaemia & 23 & 19.2 \\
Diabetes mellitus & 34 & 28.3 \\
ACE inhibitors & 70 & 58.3 \\
BB & 94 & 78.3 \\
MRA & 82 & 68.3
\end{tabular}

Note: $C H D$ - coronary heart disease; DCMP - dilated cardiomyopathy; MI - myocardial infarction; AF - atrial fibrillation; ACE inhibitors - angiotensin-converting enzyme inhibitors; BB - beta-blockers; MRA - mineralocorticoid receptors antagonists

According to the results of binary logistic regression, the predictors of BW loss of $\geq 6 \%$ in patients with $\mathrm{CHF}$ and $\mathrm{LVEF} \leq 35 \%$ were: age, coronary heart disease, the presence of concomitant anaemia, and the number of hospitalizations over the last year. Significantly higher risk of BW loss was for people with poorer quality of life and a high NYHA class, a large number of points on the Beck depression scale and the fatigue scale after physical exertion. At the same time, patients with a higher level of physical activity and a better endothelium-dependent vasodilator response had a lower risk of progressive loss of BW (Table 2).

Table 2

Predictors of BW loss $\geq 6 \%$ over the last 6 months in patients with CHF and reduced LVEF according to binary logistic regression analysis (clinical and demographic parameters)

\begin{tabular}{|c|c|c|c|c|c|}
\hline \multirow{2}{*}{ Indicator } & \multirow{2}{*}{ B (SE) } & \multirow{2}{*}{ Odds ratio } & \multicolumn{2}{|c|}{$95 \%$ confidence interval } & \multirow{2}{*}{$\mathbf{P}$} \\
\hline & & & Lower & Upper & \\
\hline 1 & 2 & 3 & 4 & 5 & 6 \\
\hline Age & $0.05(0.02)$ & 1.05 & 1.01 & 1.10 & 0.018 \\
\hline Men & $0.50(0.47)$ & 1.65 & 0.66 & 4.31 & 0.287 \\
\hline Anaemia & $1.05(0.5)$ & 2.87 & 1.12 & 8.05 & 0.034 \\
\hline Diabetes mellitus & $0.54(0.41)$ & 1.72 & 0.77 & 3.85 & 0.185 \\
\hline $\mathrm{CHD}$ & $1.21(0.61)$ & 3.37 & 1.09 & 12.67 & 0.046 \\
\hline CHD combined with hypertension & $0.97(0.53)$ & 2.63 & 0.94 & 7.40 & 0.067 \\
\hline Hypertension & $1.07(0.56)$ & 2.92 & 0.97 & 9.67 & 0.056 \\
\hline DCMP & $-1.1(0.62)$ & 0.331 & 0.099 & 1.105 & 0.072 \\
\hline $\mathrm{AF}$ & $0.01(0.37)$ & 1.01 & 0.49 & 2.08 & 0.978 \\
\hline II NYHA class & $-3.41(0.59)$ & 0.03 & 0.01 & 0.10 & $<0.001$ \\
\hline
\end{tabular}


Continuation of Table 2

\begin{tabular}{|c|c|c|c|c|c|}
\hline 1 & 2 & 3 & 4 & 5 & 6 \\
\hline III-IV NYHA class & $3.41(0.59)$ & 30.39 & 10.62 & 111.4 & $<0.001$ \\
\hline MLHFQ score & $0.08(0.02)$ & 1.08 & 1.05 & 1.12 & $<0.001$ \\
\hline Duke physical activity index & $-0.1(0.02)$ & 0.91 & 0.87 & 0.94 & $<0.001$ \\
\hline Beck Depression scale score & $0.19(0.06)$ & 1.20 & 1.08 & 1.37 & 0.002 \\
\hline DEFS score & $0.09(0.02)$ & 1.10 & 1.05 & 1.15 & $<0.001$ \\
\hline FMV & $-0.29(0.08)$ & 0.75 & 0.63 & 0.86 & $<0.001$ \\
\hline Duration of CHF & $-0.003(0.005)$ & 0.99 & 0.99 & 1.05 & 0.488 \\
\hline Duration of hypertension & $0.01(0.02)$ & 1.01 & 0.98 & 1.05 & 0.484 \\
\hline Duration of CHD & $0.001(0.03)$ & 1.01 & 0.94 & 1.06 & 0.997 \\
\hline $\begin{array}{c}\text { Number of hospitalizations over the } \\
\text { last year }\end{array}$ & $0.47(0.17)$ & 1.60 & 1.15 & 2.30 & 0.007 \\
\hline Lower limb extension test & $-0.03(0.02)$ & 0.97 & 0.93 & 1.01 & 0.130 \\
\hline 6 minute walk test & $-0.007(0.003)$ & 0.99 & 0.99 & 1.00 & 0.009 \\
\hline
\end{tabular}

Note: CHD - coronary heart disease AF - atrial fibrillation; FMV - flow-mediated vasodilation; MLHFQ - The Minnesota Living with Heart Failure Questionnaire; DEFS - Dutch Exertion Fatigue Scale

As for the anthropometric parameters, the risk of losing $\mathrm{BW} \geq 6 \%$ is lower at higher bicep circumferences of the tight and loose arm, waist and hip, SFF thicknesses above the biceps, triceps, under the shoulder blade and in the inguinal region (Table 3).

Table 3

Predictors of BW loss $\geq 6 \%$ over the last 6 months in patients with CHF and reduced LVEF according to binary logistic regression analysis (anthropometric parameters)

\begin{tabular}{|c|c|c|c|c|c|}
\hline \multirow{2}{*}{ Indicator } & \multirow{2}{*}{ B (SE) } & \multirow{2}{*}{ Odds ratio } & \multicolumn{2}{|c|}{$95 \%$ confidence interval } & \multirow{2}{*}{$\mathbf{P}$} \\
\hline & & & Lower & Upper & \\
\hline The circumference of the biceps of relaxed arm & $-0.31(0.07)$ & 0.74 & 0.64 & 0.83 & $<0.001$ \\
\hline The circumference of the biceps of tight arm & $-0.31(0.06)$ & 0.74 & 0.64 & 0.83 & $<0.001$ \\
\hline Waist circumference & $-0.06(0.02)$ & 0.94 & 0.91 & 0.97 & $<0.001$ \\
\hline Hip circumference & $-0.24(0.05)$ & 0.79 & 0.71 & 0.86 & $<0.001$ \\
\hline SFF thickness over biceps & $-0.16(0.05)$ & 0.85 & 0.77 & 0.93 & 0.001 \\
\hline SFF thickness over triceps & $-0.13(0.03)$ & 0.88 & 0.83 & 0.93 & $<0.001$ \\
\hline SFF thickness under the shoulder blade & $-0.09(0.02)$ & 0.92 & 0.88 & 0.96 & $<0.001$ \\
\hline SFF thickness in the inguinal region & $-0.05(0.02)$ & 0.95 & 0.91 & 0.98 & 0.001 \\
\hline
\end{tabular}

Note: SFF-skin-fat fold

An analysis of laboratory parameters revealed that higher levels of C-reactive protein (CRP), uric acid, as well as aspartate aminotransferase (AST) in our patients were significantly associated with a risk of losing $\mathrm{BW} \geq 6 \%$ among them. It was also found that higher levels of haemoglobin, hematocrit, cholesterol, triglycerides and albumin were associated with a lower risk of BW loss among studied patients (Table 4).

When studying hemodynamic and echocardiographic parameters, it was determined that the risk of losing $\mathrm{BW} \geq 6 \%$ in our patients increases with an increase in the size of the right atrium, right ventricle, pulmonary artery systolic pressure, and E/E'. At the same time, higher rates of diastolic blood pressure, TAPSE, and the ratio of TAPSE to pulmonary arterial systolic pressure (PASP) are associated with a reduced risk of loss of $\mathrm{BW} \geq 6 \%$ (Table 5). 
Table 4

Predictors of BW loss of $\geq 6 \%$ over the last 6 months in patients with CHF and reduced LVEF according to binary logistic regression analysis (laboratory parameters)

\begin{tabular}{cccccc}
\hline \multirow{2}{*}{ Indicator } & \multirow{2}{*}{$\mathbf{B}(\mathbf{S E})$} & Odds ratio & \multicolumn{2}{c}{$\mathbf{9 5}$ \% confidence interval } & \multirow{2}{*}{$\mathbf{P}$} \\
\cline { 4 - 5 } & & & Lower & Upper & \\
\hline Haemoglobin & $-0.02(0.01)$ & 0.98 & 0.96 & 0.99 & $\mathbf{0 . 0 2 3}$ \\
Hematocrit & $-7.2(3.05)$ & 0.001 & 0.001 & 0.30 & $\mathbf{0 . 0 1 9}$ \\
Lymphocytes, $\%$ & $-0.02(0.02)$ & 0.98 & 0.94 & 1.02 & 0.291 \\
Potassium & $0.95(0.56)$ & 2.59 & 0.90 & 8.14 & 0.087 \\
Uric acid & $0.004(0.001)$ & 1.004 & 1.001 & 1.007 & $\mathbf{0 . 0 0 6}$ \\
Bilirubin & $0.02(0.01)$ & 1.02 & 0.99 & 1.10 & 0.199 \\
AST & $0.05(0.02)$ & 1.05 & 1.02 & 0.68 & $\mathbf{0 . 0 1 0}$ \\
Cholesterol & $-0.8(0.22)$ & 0.45 & 0.28 & 0.65 & $<\mathbf{0 . 0 0 1}$ \\
Triglycerides & $-1.27(0.46)$ & 0.28 & 0.11 & 0.92 & $\mathbf{0 . 0 0 6}$ \\
Albumin & $-0.18(0.05)$ & 0.84 & 0.75 & 1.30 & $\mathbf{0 . 0 0 1}$
\end{tabular}

Note: AST - aspartate aminotransferase; $C R P-C$-reactive protein

Table 5

Predictors of BW loss $\geq 6 \%$ over the past 6 months in patients with CHF and reduced LVEF according to binary logistic regression analysis (hemodynamic and echocardiographic parameters)

\begin{tabular}{|c|c|c|c|c|c|}
\hline \multirow{2}{*}{ Indicator } & \multirow{2}{*}{ B (SE) } & \multirow{2}{*}{ Odds ratio } & \multicolumn{2}{|c|}{$95 \%$ confidence interval } & \multirow{2}{*}{$\mathbf{P}$} \\
\hline & & & Lower & Upper & \\
\hline SBP & $-0.01(0.02)$ & 0.99 & 0.96 & 1.02 & 0.598 \\
\hline DBP & $-0.06(0.03)$ & 0.94 & 0.89 & 0.99 & 0.015 \\
\hline HR & $-0.01(0.01)$ & 0.99 & 0.97 & 1.01 & 0.338 \\
\hline LVEF & $-0.04(0.03)$ & 0.963 & 0.910 & 1.019 & 0.189 \\
\hline LA & $0.43(0.3)$ & 1.54 & 0.85 & 2.79 & 0.158 \\
\hline LA volume & $0.002(0.004)$ & 1.002 & 0.99 & 1.01 & 0.554 \\
\hline LV EDVI & $0.008(0.01)$ & 1.01 & 0.99 & 1.02 & 0.196 \\
\hline LV ESVI & $-0.001(0.003)$ & 0.99 & 0.99 & 1.01 & 0.625 \\
\hline LV MMI & $-0.001(0.005)$ & 0.99 & 0.99 & 1.01 & 0.912 \\
\hline RA & $0.5(0.23)$ & 1.65 & 1.10 & 2.66 & 0.026 \\
\hline RV & $0.75(0.27)$ & 2.12 & 1.29 & 3.68 & 0.005 \\
\hline $\mathrm{E} / \mathrm{E}^{\prime}$ & $0.11(0.03)$ & 1.12 & 1.05 & 1.20 & 0.001 \\
\hline TAPSE & $-0.19(0.06)$ & 0.82 & 0.72 & 0.92 & 0.001 \\
\hline TAPSE/PASP & $-7.39(2.31)$ & 0.001 & 0.001 & 0.04 & 0.001 \\
\hline PASP & $0.08(0.02)$ & 1.08 & 1.04 & 1.13 & $<0.001$ \\
\hline
\end{tabular}

Note: SBP - systolic blood pressure; DBP - diastolic blood pressure; HR- heart rate; LVEF - left ventricular ejection fraction; LA - left atrium; LV EDVI - left ventricular end diastolic volume index; LV ESVI - left ventricular end-systolic volume index; $L V M M I$ - left ventricular myocardial mass index; $R A$ - right atrium; $R V$ - right ventricle; E/E' - the ratio of the maximum rate of early filling of the ventricle to the peak velocity of the lateral part of the mitral ring in the same phase of the cardiac cycle; TAPSEtricuspid annular plane systolic excursion; PASP - pulmonary arterial systolic pressure

In the multivariate regression model, the independent predictors of BW loss $\geq 6 \%$ in our patients were age, CRP level and III-IV NYHA class. However, higher cholesterol, a flow-dependent vasodilator response, and a hip circumference were associated with a lower risk of BW loss (Table 6). 
Table 6

Independent predictors of BW loss $\geq 6 \%$ over the past 6 months in patients with CHF and reduced LVEF according to multivariate analysis

\begin{tabular}{cccccc}
\hline \multirow{2}{*}{ Indicator } & \multirow{2}{*}{$\mathbf{B}(\mathbf{S E})$} & Odds ratio & \multicolumn{2}{c}{$\mathbf{9 5}$ \% confidence interval } & \multirow{2}{*}{$\mathbf{P}$} \\
\cline { 4 - 5 } & & & Lower & Upper & \\
\hline Age & $0.11(0.05)$ & 1.11 & 1.01 & 1.25 & $\mathbf{0 . 0 4 5}$ \\
III-IV NYHA class & $4.35(1.27)$ & 77.15 & 8.94 & 1377.73 & $\mathbf{0 . 0 0 1}$ \\
CRP & $0.62(0.18)$ & 1.85 & 0.38 & 2.83 & $\mathbf{0 . 0 0 1}$ \\
FMV \% & $-0.45(0.2)$ & 0.64 & 0.17 & 0.90 & $\mathbf{0 . 0 2 3}$ \\
Cholesterol & $-0.88(0.40)$ & 0.42 & 0.62 & 0.90 & $\mathbf{0 . 0 2 8}$ \\
Hip circumference & $-0.26(0.09)$ & 0.77 & & 0.004
\end{tabular}

\section{Discussion}

The study allowed us to confirm data on the association of BW loss in patients with CHF and reduced LVEF with age. It is known that muscle loss increases with age, as protein synthesis levels in the body decrease, which is a consequence of the ongoing decline in testosterone and other anabolic hormones $[17,18]$. The loss of BW accompanied CHF is observed much more often in patients III-IV NYHA class and is associated with their worst functionality according to the 6-minute walk test and the assessment of the physical activity index using the DASI questionnaire, which is reflected in the worse quality of life of such patients.

The relationship we found between the loss of BW in patients with $\mathrm{CHF}$ and impaired function of the right heart is confirmed in previous studies $[19,20]$. According to the data of M. Valentova and colleagues, right ventricular failure is hemodynamically associated with venous hyperaemia of the gastrointestinal tract. Edema of the intestinal mucosa is associated with abdominal discomfort, loss of appetite and postprandial satiety, which entails a deterioration in food intake and a progression in loss of BW [21]. The second mechanism, according to which venous congestion in the intestinal wall can contribute to the development of cardiac cachexia, lies through the production of pro-inflammatory cytokines induced by lipopolysaccharides [22]. Researchers suggest that chronic intestinal hyperaemia, which is determined by cardiac cachexia, contributes to the constant translocation of lipopolysaccharides into the bloodstream even in stable patients. Detection of higher serum CRP levels in patients with cachexia that correlated with a larger intestinal wall thickness confirms this point of view [21].

The role of main pathology (CHD) as a predictor of BW loss in patients with CHF can be considered from the point of view of the generality of their pathophysiological mechanisms, in particular, pro-inflammatory activation. It is known that inflammation plays an important role in the progression of atherosclerosis; highly sensitive C-reactive protein is an important risk factor for systemic atherosclerosis and is associated with its clinical complications [23, 24]. In the pathogenesis of heart failure, activation of the immune system also plays a significant role [25], plasma CRP level is increased in patients with heart failure. The results of the study show that patients with higher CRP show signs of more severe heart failure [26]. There is also evidence that an elevated CRP level independently predicts unintended weight loss [5]. CRP is a product of inflammation, the synthesis of which is stimulated by the liver in cytokines in response to an inflammatory stimulus [27]. Interleukin-6 is the main determinant of CRP production [28] in the liver and is produced in monocytes, macrophages, endothelial cells, vascular smooth muscle cells, fibroblasts and heart myocytes under hypoxic stress [29]. Left ventricular dysfunction, liver or kidney damage caused by low cardiac output, hypoperfusion, hypoxia and venous congestion can stimulate the production of interleukin-6 and, therefore, CRP production [30]. It is also possible that the relationship between plasma CRP and heart failure is causal. CRP can activate the complement system and stimulate the production of cytokines [27], thus causing myocyte apoptosis and contributing to remodeling and left ventricular dysfunction. It was shown that CRP inhibits the production of nitric oxide [31] and has a direct pro-inflammatory effect on human endothelial cells [32], disrupting their function, which is reflected in our results regarding flow-dependent vasodilation. The pathophysiological 
mechanism of endothelial dysfunction (ED) in CHF is associated with a state of increased oxidative stress in this patient population through a variety of mechanisms - reduced nitric oxide (NO) synthesis with the possible involvement of genetic polymorphism of endothelial nitric oxide synthase (eNOS) [33], oxidative NO inactivation [34], increased activity of endothelium-bound xanthine oxidase and decreased activity of extracellular superoxide dismutase [35]. Discussing the fact of the conjugation of the cachectic process and ED, the latter can be interpreted from at least two points of view. On the one hand, ED, reducing the ability to regulate peripheral blood flow in skeletal muscles, contributes to the deterioration of perfusion, and, consequently, the conditions for the loss of their mass [36]. On the other hand, there is no reason not to evaluate ED in such patients as a concomitant factor (the "role of a witness"), since along with a decrease in body weight with the clinical progression of CHF, the state of endothelial function worsens to the same extent [37].

The role of cholesterol as a factor associated with the preservation of BW in CHF can be associated with the ability to reduce the biological activity of lipopolysaccharides and, consequently, the level of inflammatory cytokines [38]. This may partially explain why low serum cholesterol is an independent prognostic factor for poor outcome in CHF [39].

Study limitations. A limitation of the study is the fact that the data on changes in body weight of some patients were based on their statements due to the lack of measured values in medical records, which could potentially be a source of inaccuracies. The lack of information in medical data cannot be completely avoided in real clinical practice. However, it was shown that the anthropometric data provided personally by the patient are suitable for use in clinical trials, since the differences are considered small compared with the measured values [40].

\section{Conclusions}

1. Weight loss $\geq 6 \%$ is observed in $49.2 \%$ of patients with $\mathrm{CHF}$ and $\mathrm{LVEF} \leq 35 \%$. In addition to the older age, its clinical predictors are NYHA class, coronary artery disease, and anaemia.

2. According to a univariate regression analysis, patients with a worse score for quality of life, a large number of points on the Beck depression scale and the fatigue scale after physical exertion have a higher risk of losing $\mathrm{BW} \geq 6 \%$. The risk of developing progressive $\mathrm{BW}$ loss is also associated with poorer functional status of patients (6-minute walk test, DASI index) and endothelium-dependent vasodilator response; this risk is reduced at higher values of the bicep circumference of a tight and relaxed arm, waist and hip, SFF thicknesses above the biceps, triceps, under the shoulder blade and in the inguinal region.

3. The risk of losing BW is associated with higher levels of CRP, uric acid, as well as aspartate aminotransferase (AST), and decreased levels of haemoglobin, hematocrit, cholesterol, triglycerides, and albumin. The risk of losing $\mathrm{BW} \geq 6 \%$ in our patients increases with an increase in the size of the right atrium, right ventricle, systolic pressure in the pulmonary artery, and E/E'. Higher diastolic blood pressure, TAPSE, and TAPSE to pulmonary systolic pressure ratios are associated with a lower risk of BW loss $\geq 6 \%$.

4. According to multivariate analysis, independent predictors of $\mathrm{BW}$ loss of $\geq 6 \%$ in patients with $\mathrm{CHF}$ and $\mathrm{LVEF} \leq 35 \%$ are age, CRP, III-IV NYHA class, lower cholesterol levels, as well as lower rates of flow-dependent vasodilator response and hip circumference.

\section{Conflict of interest}

No conflict of interest.

\section{References}

[1] Dube, P., Weber, K. T., Weber, K. T. (2011). Congestive Heart Failure: Pathophysiologic Consequences of Neurohormonal Activation and the Potential for Recovery: Part II. The American Journal of the Medical Sciences, 342 (6), 503-506. doi: http:// doi.org/10.1097/maj.0b013e3182327527

[2] Okoshi, M. P., Romeiro, F. G., Paiva, S. A., Okoshi, K. (2013). Heart failure induced cachexia. Arquivos Brasileiros De Cardiologia, 100, 476-482. doi: http://doi.org/10.5935/abc.20130060

[3] Stewart Coats, A. J., Shewan, L. G. (2017). A comparison of research into cachexia, wasting and related skeletal muscle syndromes in three chronic disease areas. International Journal of Cardiology, 235, 33-36. doi: http://doi.org/10.1016/j.ijcard.2017.02.136 
[4] Anker, S. D., Negassa, A., Coats, A. J., Afzal, R., Poole-Wilson, P. A., Cohn, J. N., Yusuf, S. (2003). Prognostic importance of weight loss in chronic heart failure and the effect of treatment with angiotensin-converting-enzyme inhibitors: an observational study. The Lancet, 361 (9363), 1077-1083. doi: http://doi.org/10.1016/s0140-6736(03)12892-9

[5] Song, E. K., Lee, Y., Moser, D. K., Dekker, R. L., Kang, S.-M., Lennie, T. A. (2014). The Link of Unintentional Weight Loss to Cardiac Event-Free Survival in Patients With Heart Failure. The Journal of Cardiovascular Nursing, 29 (5), $439-447$. doi: http://doi.org/10.1097/jen.0b013e3182a46ba8

[6] Von Haehling, S., Anker, S. D. (2010). Cachexia as a major underestimated and unmet medical need: facts and numbers. Journal of Cachexia, Sarcopenia and Muscle, 1 (1), 1-5. doi: http://doi.org/10.1007/s13539-010-0002-6

[7] Szabó, T., Postrach, E., Mähler, A., Kung, T., Turhan, G., von Haehling, S. et. al. (2013). Increased catabolic activity in adipose tissue of patients with chronic heart failure. European Journal of Heart Failure, 15 (10), 1131-1137. doi: http://doi.org/10.1093/eurjhf/hft067

[8] Ponikowski, P., Voors, A. A., Anker, S. D., Bueno, H., Cleland, J. G. F., Coats, A. J. S. et. al. (2016). ESC Guidelines for the diagnosis and treatment of acute and chronic heart failure: The Task Force for the diagnosis and treatment of acute and chronic heart failure of the European Society of Cardiology (ESC). European Heart Journal, 37 (27), 2129-2200. doi: http://doi.org/ 10.1093/eurheartj/ehw128

[9] Voronkov, L. H. et. al. (Eds.) (2017). Rekomendatsii Asotsiatsii kardiolohiv Ukrainy z diahnostyky ta likuvannia khronichnoi sertsevoi nedostatnosti. Kyiv, 66.

[10] Kovalenko, V. M., Ivaniv, Yu. A.; Kovalenko, V. M. et. al. (Eds.) (2015). Rekomendatsii robochoi hrupy z funktsionalnoi diahnostyky asotsiatsii kardiolohiv Ukrainy i Vseukrainskoi asotsiatsii fakhivtsiv z ekhokardiohrafii. Kyiv.

[11] Stevens, L. A., Coresh, J., Greene, T., Levey, A. S. (2006). Assessing Kidney Function - Measured and Estimated Glomerular Filtration Rate. New England Journal of Medicine, 354 (23), 2473-2483. doi: http://doi.org/10.1056/nejmra054415

[12] Voronkov, L. G., Parascheniuk, L. P. (2010). Kachestvo zhizni pri serdechnoi nedostatochnosti: aktualnye aspekty. Serceva nedostatnist, 2, 12-16.

[13] Gilarevsky, S. R., Orlov, V. A., Bendeliani, N. G., Hamaganova, L. K., Sycheva, E. Y. (2001). A Study of life quality in patients with chronic heart failure: the contemporary status. Russian Journal of Cardiology, 3, 58-72.

[14] Vatutin, N. T., Kalinkina, N. V., Kartamysheva, Ye. V., Khristichenko, M. A., Yeshchenko, Ye. V. (2013). Depressive disorders and chronic heart failure. Ukrainian Journal of Cardiology, 3, 117-124.

[15] Tiesinga, L. J., Dassen, T. W. N., Halfens, R. J. G. (1998). DUFS and DEFS: development, reliability and validity of the Dutch Fatigue Scale and the Dutch Exertion Fatigue Scale. International Journal of Nursing Studies, 35 (1-2), 115-123. doi: http:// doi.org/10.1016/s0020-7489(98)00005-4

[16] Voronkov, L. G., Shkurat, I. A., Besaga, E. M. (2005). Endothelium-dependent vasodilatation and its prognostic value in patients with chronic heart failure and left ventricular systolic dysfunction. Ukrainian Journal of Cardiology, 6, 86-90.

[17] Cavey, J. (2011). Cardiac Cachexia. The Journal for Nurse Practitioners, 7 (7), 578-581. doi: http://doi.org/10.1016/j.nurpra.2011.04.018

[18] Yamada, M., Nishiguchi, S., Fukutani, N., Tanigawa, T., Yukutake, T., Kayama, H. et. al. (2013). Prevalence of Sarcopenia in Community-Dwelling Japanese Older Adults. Journal of the American Medical Directors Association, 14 (12), 911-915. doi: http://doi.org/10.1016/j.jamda.2013.08.015

[19] Melenovsky, V., Kotrc, M., Borlaug, B. A., Marek, T., Kovar, J., Malek, I., Kautzner, J. (2013). Relationships Between Right Ventricular Function, Body Composition, and Prognosis in Advanced Heart Failure. Journal of the American College of Cardiology, 62 (18), 1660-1670. doi: http://doi.org/10.1016/j.jacc.2013.06.046

[20] Valentova, M., von Haehling, S., Krause, C., Ebner, N., Steinbeck, L., Cramer, L. et. al. (2013). Cardiac cachexia is associated with right ventricular failure and liver dysfunction. International Journal of Cardiology, 169 (3), 219-224. doi: http://doi. org/10.1016/j.ijcard.2013.08.134

[21] Valentova, M., von Haehling, S., Bauditz, J., Doehner, W., Ebner, N., Bekfani, T. et. al. (2016). Intestinal congestion and right ventricular dysfunction: a link with appetite loss, inflammation, and cachexia in chronic heart failure. European Heart Journal, 37 (21), 1684-1691. doi: http://doi.org/10.1093/eurheartj/ehw008

[22] Liu, X., Yin, S., Chen, Y., Wu, Y., Zheng, W., Dong, H. et. al. (2018). LPS-induced proinflammatory cytokine expression in human airway epithelial cells and macrophages via NF- ${ }^{-} \mathrm{B}$, STAT3 or AP-1 activation. Molecular Medicine Reports, 17 (4), 5484-5491. doi: http://doi.org/10.3892/mmr.2018.8542

[23] Shrivastava, A. K., Singh, H. V., Raizada, A., Singh, S. K. (2015). C-reactive protein, inflammation and coronary heart disease. The Egyptian Heart Journal, 67 (2), 89-97. doi: http://doi.org/10.1016/j.ehj.2014.11.005

[24] Ridker, P. M., Rifai, N., Rose, L., Buring, J. E., Cook, N. R. (2002). Comparison of C-Reactive Protein and Low-Density Lipoprotein Cholesterol Levels in the Prediction of First Cardiovascular Events. New England Journal of Medicine, 347 (20), 1557-1565. doi: http://doi.org/10.1056/nejmoa021993 
[25] Kalogeropoulos, A., Georgiopoulou, V., Psaty, B. M., Rodondi, N., Smith, A. L., Harrison, D. G. et. al. (2010). Inflammatory Markers and Incident Heart Failure Risk in Older Adults: The Health, Aging, and Body Composition Study. Journal of the American College of Cardiology, 55 (19), 2129-2137. doi: http://doi.org/10.1016/j.jacc.2009.12.045

[26] Anand, I. S., Latini, R., Florea, V. G., Kuskowski, M. A., Rector, T., Masson, S. et. al. (2005). C-Reactive Protein in Heart Failure Prognostic Value and the Effect of Valsartan. Circulation, 112 (10), 1428-1434. doi: http://doi.org/10.1161/circulationaha.104.508465

[27] Sproston, N. R., Ashworth, J. J. (2018). Role of C-Reactive Protein at Sites of Inflammation and Infection. Frontiers in Immunology, 9. doi: http://doi.org/10.3389/fimmu.2018.00754

[28] Eklund, C. M. (2009). Chapter 5 Proinflammatory cytokines in CRP baseline regulation. Advances in Clinical Chemistry, 48, 111-136. doi: http://doi.org/10.1016/s0065-2423(09)48005-3

[29] Yamauchi-Takihara, K., Ihara, Y., Ogata, A., Yoshizaki, K., Azuma, J., Kishimoto, T. (1995). Hypoxic Stress Induces Cardiac Myocyte-Derived Interleukin-6. Circulation, 91 (5), 1520-1524. doi: http://doi.org/10.1161/01.cir.91.5.1520

[30] Deokar, S. A., Dandekar, S. P., Shinde, G. A., Prabhu, S. S., Patawardhan, M. (2018). Role of serum interleukin-6 in heart failure. International Journal of Advances in Medicine, 5 (4), 936-940. doi: http://doi.org/10.18203/2349-3933.ijam20183123

[31] Sproston, N. R., El Mohtadi, M., Slevin, M., Gilmore, W., Ashworth, J. J. (2018). The Effect of C-Reactive Protein Isoforms on Nitric Oxide Production by U937 Monocytes/Macrophages. Frontiers in Immunology, 9. doi: http://doi.org/10.3389/fimmu.2018.01500

[32] Pasceri, V., Willerson, J. T., Yeh, E. T. H. (2000). Direct Proinflammatory Effect of C-Reactive Protein on Human Endothelial Cells. Circulation, 102 (18), 2165-2168. doi: http://doi.org/10.1161/01.cir.102.18.2165

[33] Fedele, F., Mancone, M., Chilian, W. M., Severino, P., Canali, E., Logan, S. et. al. (2013). Role of genetic polymorphisms of ion channels in the pathophysiology of coronary microvascular dysfunction and ischemic heart disease. Basic Research in Cardiology, 108 (6). doi: http://doi.org/10.1007/s00395-013-0387-4

[34] Park, K.-H., Park, W. J. (2015). Endothelial Dysfunction: Clinical Implications in Cardiovascular Disease and Therapeutic Approaches. Journal of Korean Medical Science, 30 (9), 1213-1225. doi: http://doi.org/10.3346/jkms.2015.30.9.1213

[35] Landmesser, U., Spiekermann, S., Dikalov, S., Tatge, H., Wilke, R., Kohler, C. et. al. (2002). Vascular Oxidative Stress and Endothelial Dysfunction in Patients With Chronic Heart Failure. Circulation, 106 (24), 3073-3078. doi: http://doi.org/10.1161/ 01.cir.0000041431.57222.af

[36] Timmerman, K. L., Volpi, E. (2013). Endothelial function and the regulation of muscle protein anabolism in older adults. Nutrition, Metabolism and Cardiovascular Diseases, 23, S44-S50. doi: http://doi.org/10.1016/j.numecd.2012.03.013

[37] Dos Santos, M. R., Saitoh, M., Ebner, N., Valentova, M., Konishi, M., Ishida, J. et. al. (2017). Sarcopenia and Endothelial Function in Patients With Chronic Heart Failure: Results From the Studies Investigating Comorbidities Aggravating Heart Failure (SICA-HF). Journal of the American Medical Directors Association, 18 (3), 240-245. doi: http://doi.org/10.1016/ j.jamda.2016.09.006

[38] Zhao, Q., Li, J., Yang, J., Li, R. (2017). Association of total cholesterol and HDL-C levels and outcome in coronary heart disease patients with heart failure. Medicine, 96 (9), e6094. doi: http://doi.org/10.1097/md.0000000000006094

[39] Azhar, G., Wei, J. Y. (2013). New Approaches to Treating Cardiac Cachexia in the Older Patient. Current Cardiovascular Risk Reports, 7 (6), 480-484. doi: http://doi.org/10.1007/s12170-013-0353-6

[40] Wright, F. L., Green, J., Reeves, G., Beral, V., Cairns, B. J. (2015). Validity over time of self-reported anthropometric variables during follow-up of a large cohort of UK women. BMC Medical Research Methodology, 15 (1). doi: http://doi.org/10.1186/ s12874-015-0075-1 